\section{Danza para los ojos azules. Dance for blue eyes}

\author{
Yasna Vergara Ossa \\ Profesora en la Escuela de danza UAHC \\ Universidad Academia de \\ Humanismo Cristiano, Chile. \\ vergaraossa@yahoo.com
}

Recibido 05/10/2016

Aceptado 05/11/2016
Revisado 05/11/2016

Publicado 01/01/2017

\section{Resumen}

La danza de los ojos azules es producto de un proceso creativo llevado a cabo en el año 2014 por estudiantes de distintas generaciones de la Escuela de danza Espiral y la Universidad Academia de Humanismo Cristiano en Santiago de Chile. Su origen se arraiga en la visión cultural y espíritu artístico de sus fundadores, Patricio Bunster y Joan Turner, quienes en contexto político adverso en la Historia de Chile siguen una formación que pudiera recuperar, congregar y acercar la danza a sectores sin acceso al goce de este arte. Espiral contribuyó al restablecimiento de la tradición de extensión cultural en Chile, abriendo un espacio de desarrollo para el arte hacia diversos sectores sin imponer formas ni estilos, extendiendo la posibilidad
The blue eyes dance is a product of a creative process carried out in 2014 by students of different generations of the School of Dance Spiral and the University Academy of Christian Humanism in Santiago de Chile. Its origin is comes from the cultural vision and artistic spirit of its founders, Patricio Bunster and Joan Turner, who in an adverse political context in the history of Chile follow a formation to recover, congregate and bring dance to sectors without access to the artistic practice. Espiral contributed to the restoration of the tradition of cultural extension in Chile, opening a space for the development of art towards different sectors without imposing forms or styles, extending the possibility of recovery of the 
de recuperación de la cultura artística a través de perspectivas de crecimiento, conocimiento e identidad. artistic culture through perspectives of growth, knowledge and identity.

Palabras clave / Keywords

Danza, educación, memoria histórica.

Dance, education, historical memory. 


\section{Sinopsis}

El acto de recordar es el retorno a nosotros mismos mirándonos a través del entretejido de nuestra existencia y el tiempo que ha registrado nuestra historia. Al volver a nuestros recuerdos, el lugar de la memoria nos habita en conexión sensible con afectos, hitos y lugares que reconocemos como propios y en comunión con otros, siendo nuestra historia y nuestra cultura lo que nos construye y reconstruye constantemente. Allí, en nuestro ser y estar, reconocemos signos y símbolos que se multiplican a través del tiempo presente y en nuestro comunicarnos, en vivirnos y habitarnos. Los significados hablan en nuestro lenguaje, el lenguaje de la danza que habitamos en carne, en memoria y en historia. En nuestra historia y en nuestra danza. La danza de la Escuela Espiral.

Situada en lugar de reconocimiento patrimonial por la comunidad de la danza en Chile y por quienes han transitado en sus aulas, Espiral, creado en 1985, forma parte de la educación de la danza en Chile conformándose en una escuela que posee un rasgo que la identifica a través de su origen, sus fundadores, su particular historia y su forma de enseñanzaaprendizaje en la constante retroalimentación de danzar, habitando historias individuales y colectivas que le han concedido trascendencia en el tiempo como fenómeno cultural de la danza cuya acción y pensamiento, abarcan tanto la formación de aficionados como de profesionales acercando la danza a distintos ámbitos de expresión social.

Su origen se arraiga a la visión cultural y espíritu artístico de sus fundadores, Patricio Bunster y Joan Turner, quienes luego de volver del exilio, retomaron su labor de reinserción de la danza en un contexto político adverso en la historia de Chile.

Haciendo énfasis en una formación que pudiera recuperar, congregar y acercar la danza a sectores sin acceso al goce de este arte, en sus inicios Espiral contribuyó al restablecimiento de la tradición de extensión cultural en Chile, en donde a través de su visión de enseñanza se abrió un espacio de desarrollo para el arte hacia diversos sectores sociales no imponiendo formas ni estilos estáticos sino que extendiendo la posibilidad de recuperación de la cultura artística a través de perspectivas de crecimiento, conocimiento e identidad.

El constante trazado entre cuerpo, tiempo y espacio vivido de la danza que habita a Espiral ha sustentado su existencia desde diversas formas e hitos que marcan su trayectoria formativa. Evolución y crecimiento que deja entrever la lectura de simbolismos e interpretaciones alojadas en la memoria de quienes han formado parte de esta educación en cuanto a espacio-tiempo y experiencia vivida desde sus diversas connotaciones como lugar 
para la educación de la danza. Asimismo, su acción, reflejo de su ideología y autonomía se propaga en los distintos sectores y geografías a través de los profesionales egresados que llevan a la práctica y comparten la danza desde su constante originaria; espiral en evolución y crecimiento, conceptos que se resignifican desde su sentido histórico y simbólico en el entretejido de vivencias y conocimientos en conexión con el arte que esta escuela tiene por esencia.

Danza para los ojos azules es producto de un proceso creativo llevado a cabo en el año 2014 con estudiantes de distintas generaciones de la Escuela de danza Espiral y la Universidad Academia de Humanismo Cristiano en Santiago de Chile.

Dicho proceso tuvo como propósito hacer conexión entre cuerpo, espacio y memoria valorando el sentido educativo y colectivo de la danza reunida en diversidad y riqueza corporal, la cual desde su armonía y poética danza en un ritual de celebración de la vida y el renacer constante, en espiral, de la Maestra Joan Jara, origen de este vuelo creativo.

Hoy, dos años después, quienes formaron parte de danza para los ojos azules vuelven a sí mismos, recuerdan desde sus propias interpretaciones y dan nuevo significado al danzar juntos.

\section{Créditos:}

Idea original, creación danzada y dirección general: Yasna Vergara Ossa

Realización y dirección audiovisual: Máximo Hernández Vera
Musicalización: Manuel Casazola Huancco, Claudio Araya. Arreglos e interpretación: Claudio Araya

Estudiantes intérpretes: Diego Aranda, Raúl Órdenes, Camilo Rodríguez, Dalton San Martín, Rodrigo Sepúlveda, Rubén Calixto, Alfredo Espejo, Gonzalo Muñoz, Isabel Arcos, Janet Barriga, Paula Guzmán, Natalia Herrera, Pamela Moraga, Carolina Olivares, Sandra Orellana, Carola Silva, Daniela Báez, Ivanna Corro, Valeska Castillo, Rocío Espejo, Vicenta Pavez

Estudiantes entrevistados: Diego Aranda, Valeska Castillo, Sandra Orellana, Dalton San Martín, Rodrigo Sepúlveda

Imágenes originales y locaciones: Desierto de Atacama, ruinas oficina salitrera Prat. Sala de danza escuela Espiral. Plaza Brasil. Sala de danza-auditorium escuela de danza UAHC. Localidad de Rapel

Imágenes de archivo: Máximo Hernández, Yasna Vergara, Manuela Bunster

Duración: 20’30”

\section{Agradecimientos:}

Estudiantes escuela de danza UAHC

Centro de danza Espiral

Compañía de danza Espiral

Escuela de danza y Facultad de artes UAHC 


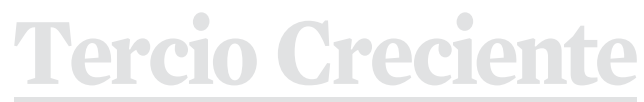

ISSN: 2340-9096

DOI: $10.17561 /$ rtc.n11.2
Revista de Estudios en Sociedad, Artes y Gestión Cultural

Número 11

Enero 2017

www.terciocreciente.com

http://revistaselectronicas. ujaen.es/index.php/RTC

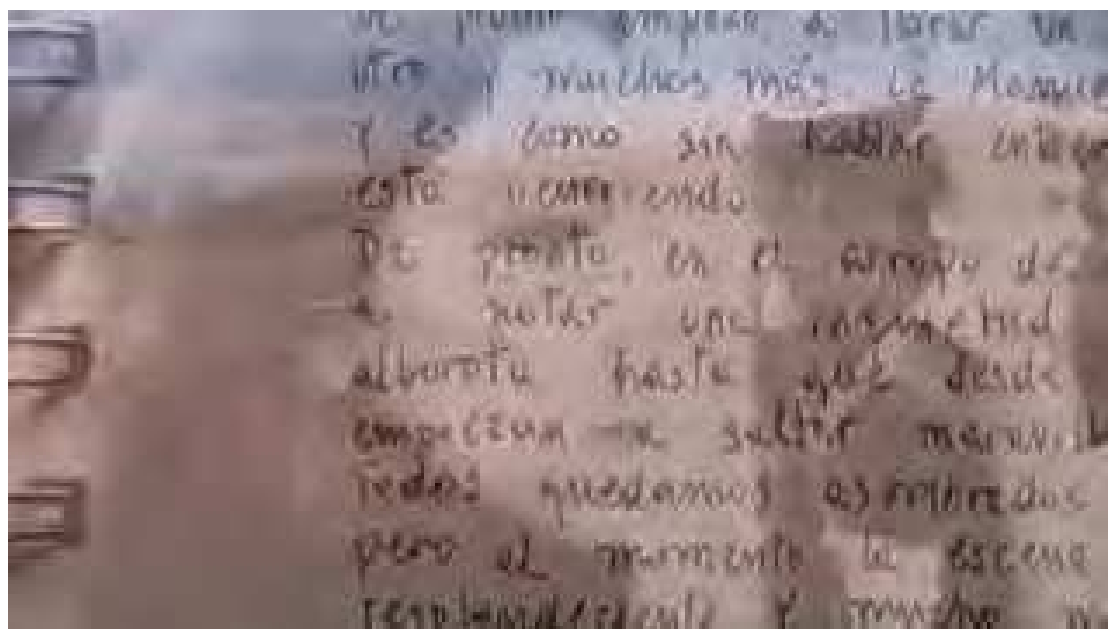

https://youtu.be/ya_QbcJpR7Q 
Revista de Estudios en Sociedad, Artes y Gestión Cultural

ISSN: 2340-9096

DOI: $10.17561 /$ rtc.n11.2
http://revistaselectronicas.ujaen.es/index.php/RTC www.terciocreciente.com
Número 11

Enero 2017

Ensayo 